\title{
Desenvolvimento de bancada didática contendo múltiplos sensores e atuadores
}

\author{
Development of a teaching bench containing multiple sensors and actuators \\ Desarrollo de un banco de enseñanza que contiene múltiples sensores y actuadores
}

Recebido: 2809/2021 | Revisado: 04/10/2021 | Aceito: 07/10/2021 | Publicado: 10/10/2021

André Gurgel Pinho
ORCID: https://orcid.org/0000-0002-6408-3867
Enstituto Federal de Educação, Ciência e Tecnologia de Goiás, Brasil
E-mail: andregurgelpinho@gmail.com
Edmar Júnior Silva Olímpio
ORCID: https://orcid.org/0000-0002-8712-9477
E-mail: edmarolimpio@gmail.com
Lucas Moreira Cabral
Instituto Federal de Educação, Ciência e Tecnologia de Goís, Brasil
ORCID: https://orcid.org/0000-0003-0971-3691
E-mail: lucas.m.cabral@gmail.com
Instituto Federal de Educação, Ciência e Tecnologia de Goiá, Brasil
Renato Milhomem de Oliveira Filho
ORCID: https://orcid.org/0000-0003-3351-1176
E-mail: rmoliveira17@gmail.com
Brunna Carolinne Rocha Silva
ORCID: https://orcid.org/0000-0003-1654-5980
Instituto Federal de Educação, Ciência e Tecnologia de Goiás, Brasil
E-mail: brunnac.rocha@gmail.com
Geovanne Pereira Furriel
Instituto Federal de Educação, Ciência e Tecnologia de Goias, Brasil
ORCID: https://orcid.org/0000-0002-8510-1024
Enstituto Federal de Educação, Ciência e Tecnologia de Goiás, Brasil
E-mail: geovanne.furriel@ifgoiano.edu.br
Gilberto de Melo Junior
ORCID: https://orcid.org/0000-0002-2317-7779
E-mail: gilberto.melo@ifpa.edu.br

\section{Resumo}

Bancadas didáticas são importantes ferramentas para o ensino, onde consolida o conteúdo teórico com a prática, principalmente em cursos voltados para tecnologia. Neste trabalho será apresentado o desenvolvimento de uma bancada didática utilizando sensores e atuadores, capaz de fornecer valores de medição de nível e temperatura do sistema. Obteve-se a finalização da bancada didática e elaboração de dois ensaios de testes, usando os materiais apropriados para tal, e como resultado foram atingidos os objetivos propostos, o funcionamento da bancada com a medição e cálculos das grandezas físicas através dos sensores e atuadores.

Palavras-chave: Bancada didática; Microcontrolador; Sensores; Atuadores.

\begin{abstract}
Didactic benches are important tools for teaching, where they consolidate theoretical content with practice, especially in technology-oriented courses. In this work, the development of a didactic bench using sensors and actuators, capable of providing system level and temperature measurement values will be presented. The completion of the didactic bench was achieved and two test tests were prepared, using the appropriate materials for this purpose, and as a result, the proposed objectives were achieved, the functioning of the bench with the measurement and calculation of physical quantities through sensors and actuators.
\end{abstract}

Keywords: Didactic bench; Microcontroller; Sensors; Actuators.

\section{Resumen}

Los bancos didácticos son herramientas importantes para la docencia, donde consolidan los contenidos teóricos con la práctica, especialmente en los cursos orientados a la tecnología. En este trabajo se presentará el desarrollo de un banco didáctico mediante sensores y actuadores, capaz de proporcionar valores de medición de nivel y temperatura del sistema. Se logró la finalización del banco didáctico y se prepararon dos pruebas de ensayo, utilizando los materiales adecuados para tal fin, y como resultado se lograron los objetivos propuestos, el funcionamiento del banco con la medición y cálculo de magnitudes físicas a través de sensores y actuadores.

Palabras clave: Banco didáctico; Microcontrolador; Sensores; Actuadores. 


\section{Introdução}

O mundo profissional contemporâneo tem exigido habilidades e competências para a tomada de decisões acertadas e precisas, além de criatividade na resolução de problemas inesperados e desenvolvimento de processos mais eficientes.

Esse panorama fez com que as diretrizes curriculares dos cursos de engenharias fossem modificadas na legislação brasileira - Lei No 9.394 de 20 de dezembro de 1996 (Educação, 1996), com o intuito de melhorar a efetividade do ensinoaprendizagem. Nesse âmbito, o método tradicional de transmissão de conhecimento, baseado no ensino em sala aula onde o professor é o agente transmissor e o aluno o receptor, mostra-se incompleto para a preparação de futuros profissionais (Anabuki, 2019).

Nas modificações está a ligação entre conhecimento teórico e a experimentação prática. Esses dois pilares do ensino devem ser enfatizados nos cursos de engenharia, visando sempre o melhor aproveitamento para a transferência e geração de conhecimento.

Mesmo com grande parte do ensino sendo realizado em laboratórios, a falta de objetivos de aprendizagem coerentes limitou a eficácia dos mesmos e dificultou o desenvolvimento de pesquisas significativas na área de engenharia e de aprendizagem (Feisel \& Rosa, 2005).

Paralelo a necessidade de melhorar o ensino em áreas tecnológicas, o processo de automação tem ganhado espaço em várias áreas na sociedade. Por meio disso é possível economizar tempo e recursos, além de ganhar em produtividade e qualidade nos mais variados processos e atividades. Além disso, ganhos em segurança e qualidade de vida para operadores também podem ser mencionados como vantagens da automação (Marques et al., 2018).

O crescimento dessa área fez aumentar também a demanda por engenheiros e profissionais para o desenvolvimento de sistemas com automação. Essa demanda fez com que atividades fossem desenvolvidas para melhorar cada vez mais o ensino de processos de automação em instituições de nível técnico e superior, permitindo que o educando tenha acesso à equipamentos e situações recorrentes no cotidiano de profissionais da área.

Uma das principais ferramentas que contempla esse tipo de ensino é a bancada didática, e por isso vem se difundindo gradativamente no ambiente acadêmico (Marques et al., 2018). Bancadas didáticas são ferramentas de aprendizado importantes, pois possibilitam a análise e a consolidação da teoria ensinada em sala de aula. O uso dessas bancadas auxilia no desenvolvimento de discentes de diversas áreas, principalmente nos cursos de bacharelado em engenharia, pois através delas há a possibilidade do contato com a prática, simulando processos industriais e sistemas reais (Fabián, 2017).

As bancadas abordam uma quantidade elevada de dificuldades técnicas, que são enfrentadas em situações reais no cotidiano. Com o avanço da tecnologia e do mercado, é imprescindível formar profissionais preparados e qualificados para atender as demandas do mercado de trabalho e especificadamente de industrias (Texeira et al., 2018), com isso, as bancadas didáticas se tornam grandes aliadas dos discentes de cursos de engenharia, que podem aplicar conhecimentos de algumas disciplinas específicas voltadas para instrumentação industrial.

A instrumentação industrial é a área da engenharia voltada para os processos industriais, nas leituras e medições das variáveis físicas e químicas que compõem um sistema. O intuito é controlar essas variáveis, a fim de melhorar e desenvolver, otimizando o processo (Dunn, 2013).

Ao longo dos anos, instituições de ensino, apesar de fazer aquisição, também começaram a desenvolver, alunos em conjunto com professores, bancadas didáticas específicas para a área industrial, com o intuito de suprir com suas respectivas atividades (Zorzan et al., 2013). Aulas ministradas utilizando bancada didática possibilitam visão aprofundada dos discentes em relação ao que lhes aguardam no mercado de trabalho. Também favorece aos mesmos o esclarecimento de conceitos fundamentais, facilitando o entendimento e aprendizagem de modelos para a análise dos sistemas. Assim, os estudantes são motivados quando há a oportunidade de aplicar conceitos teóricos em algo concreto, para a solução de problemas vistos em 
sala de aula, estabelecendo uma conexão entre teoria e prática.

Trabalhos e estudos ilustram a importância da utilização de bancadas didáticas no ensino. Alpi (2016) realizou em seu trabalho o controle de nível de água de tanques acoplados. A aplicação demonstra o funcionamento prático de um Controlador Proporcional, Integral e Derivativo (PID).

Goulart (2008) desenvolveu bancada para análise de desempenho térmico de trocador de calor, variando a vazão de água e fluxo de ar, armazenando suas temperaturas de entrada e saída. Sua estrutura foi composta por dois tanques, onde o primeiro aquecia a água para a realização do experimento e o segundo armazenava a água depois do processo de resfriamento.

Anderle (2017) realizou dimensionamento de bancada didática para o estudo em hidráulica. O projeto foi realizado com o intuito de oferecer nova forma de estudos para a instituição de origem, Faculdade Horizontina. Focou-se na construção de bancada com matérias de fácil acesso e presentes na instituição. Lima (2014) realizou um projeto e construção de uma bancada didático-experimental, composta por um motor elétrico, um eixo e um volante de massa, para simulação de sinais de vibrações para o estudo da manutenção preditiva. Tal bancada foi capaz de simular as condições de desalinhamento, desbalanceamento e falha em rolamento, impostas e controladas pelo usuário.

No trabalho de Toigo (2017) foi desenvolvida bancada para análise experimental de refrigeração por compressão de vapor. A captação de dados é realizada em diversos pontos diferentes da bancada. O controle pode ser feito em tempo real, a partir valores pré-estabelecidos de cargas térmicas.

No intuito do desenvolvimento dos discentes de Engenharia de Controle e Automação, Engenharia Elétrica e Engenharia Mecânica do Instituto Federal de Goiás, Campus Goiânia, será elaborado trabalho que tem como objetivo geral desenvolver e projetar bancada didática, utilizando os conhecimentos de instrumentação industrial, tendo como funcionamento básico a circulação de água entre dois tanques e um reservatório, onde serão utilizados sensores e atuadores para medir nível e temperatura de dois processos.

Como objetivos específicos tem-se:

- Realizar estudo sobre instrumentação industrial, sensores e atuadores;

- Analisar e escolher materiais adequados para o uso na bancada;

- Construir a bancada didática;

- Realizar testes propostos na bancada didática.

As seções deste trabalho estão organizadas em: Materiais e Métodos, na qual descreverá os materiais e as métodos utilizados no projeto; Resultados, apresentando os resultados do desenvolvimento da bancada e de experimentos realizados; por fim, a Conclusão, onde conclui-se e sugere trabalhos futuros.

\section{Materiais e Métodos}

O desenvolvimento da bancada didática é descrito nesse capítulo. Serão apresentados a descrição dos sensores, os atuadores e o microcontrolador utilizados no projeto, bem como o fluxograma de funcionamento da bancada. Também serão apresentados a metodologia dos experimentos que poderão ser ensaiados na bancada didática. Para este projeto foi desenvolvido um estudo de caso, com aplicação em bancada (Estrela, 2018); (Pereira et al., 2018) (Yin, 2015).

\subsection{Materiais utilizados no projeto da bancada didática}

Projetou-se a bancada com um reservatório e dois tanques em diferentes posições e alturas interligados por tubulações fabricadas em PVC. Tal estrutura foi utilizada para a realização de processos envolvendo a circulação de água.

Além dos recipientes e das tubulações, dois sensores de nível do modelo Boia e um sensor de temperatura termopar serão utilizados. Assim como sensores, atuadores também serão utilizados, dentre eles: uma bomba submersa da fabricante 
Sarlo, modelo S300 com vazão de 280 1/h, duas válvulas solenoides de 180 compatíveis com tubos de 3/4" de diâmetro e uma resistência elétrica modelo ebulidor mergulhão. Os processos serão controlados por um microcontrolador Arduino mega 2560, para proteção considerou-se disjuntor do fabricante Metalflex, modelo N3 com corrente nominal de 16A. A definição e características dos instrumentos utilizados no projeto podem ser verificados na Tabela 1 com descrição dos mesmos.

Tabela 1. Instrumentos utilizados na montagem da bancada didática.

\begin{tabular}{ccc}
\hline QUANT. & INSTRUMENTO / EQUIPAMENTO & DESCRIÇÃO \\
\hline 1 & Microcontrolador & Arduino MEGA 2560 \\
2 & Tanque Plástico & $1100 \mathrm{ml}$ \\
1 & Tanque Plástico Reservatório & $2700 \mathrm{ml}$ \\
1 & Bomba Submersa & SARLO S300 - 280 1/ h \\
1 & Sensor de temperatura & Temorpar Max 6675 \\
2 & Válvula Solenoide & $180^{\circ}-3 / 4 "-220 \mathrm{~V}$ \\
2 & Sensor de nível & Modelo Boia \\
1 & Ebulidor Mergulhão & Alumínio - 1000W / 220V - 4,55A \\
4 & Relé & Songle - SRD-0,5VDC-SL-C \\
1 & Disjuntor & Metalflex - N3 - C16A - 3kA
\end{tabular}

Fonte: Autores.

A bancada didática foi construída com estrutura de madeira, com base de 60x60x1,5 cm e torres para os tanques. Ela será constituída com um reservatório de $2700 \mathrm{ml}$ fixado em sua base, com a função de abastecer dois tanques de volume igual a $1100 \mathrm{ml}$. O Tanque 1 está a uma altura de 61,5 cm da base. O Tanque 2 está a $31,5 \mathrm{~cm}$ da base.

Foram utilizados uma bomba submersa no reservatório, sensor de nível alto nos dois tanques e sensor de temperatura no Tanque 2. Válvulas solenoides foram instaladas nas tubulações entre o Tanque 1 e o Tanque 2 , e entre o Tanque 2 e o Reservatório.

A International Society of Automation 5.1 (ISA, 2002) padroniza os símbolos de instrumentos que deverão ser utilizados em diagramas de projetos de instrumentação. A ISA 5.1 é aplicada nos Diagramas $P \& I$, em português, Diagrama de Processos e Instrumentação ou Fluxograma de Engenharia (Tôrres, 2006).

A Figura 1 ilustra o Diagrama $P \& I$ da bancada. Figuras 2 e 3 apresentam as vistas da bancada didática projetada. 
Figura 1. Diagrama P\&I da Bancada Didática.

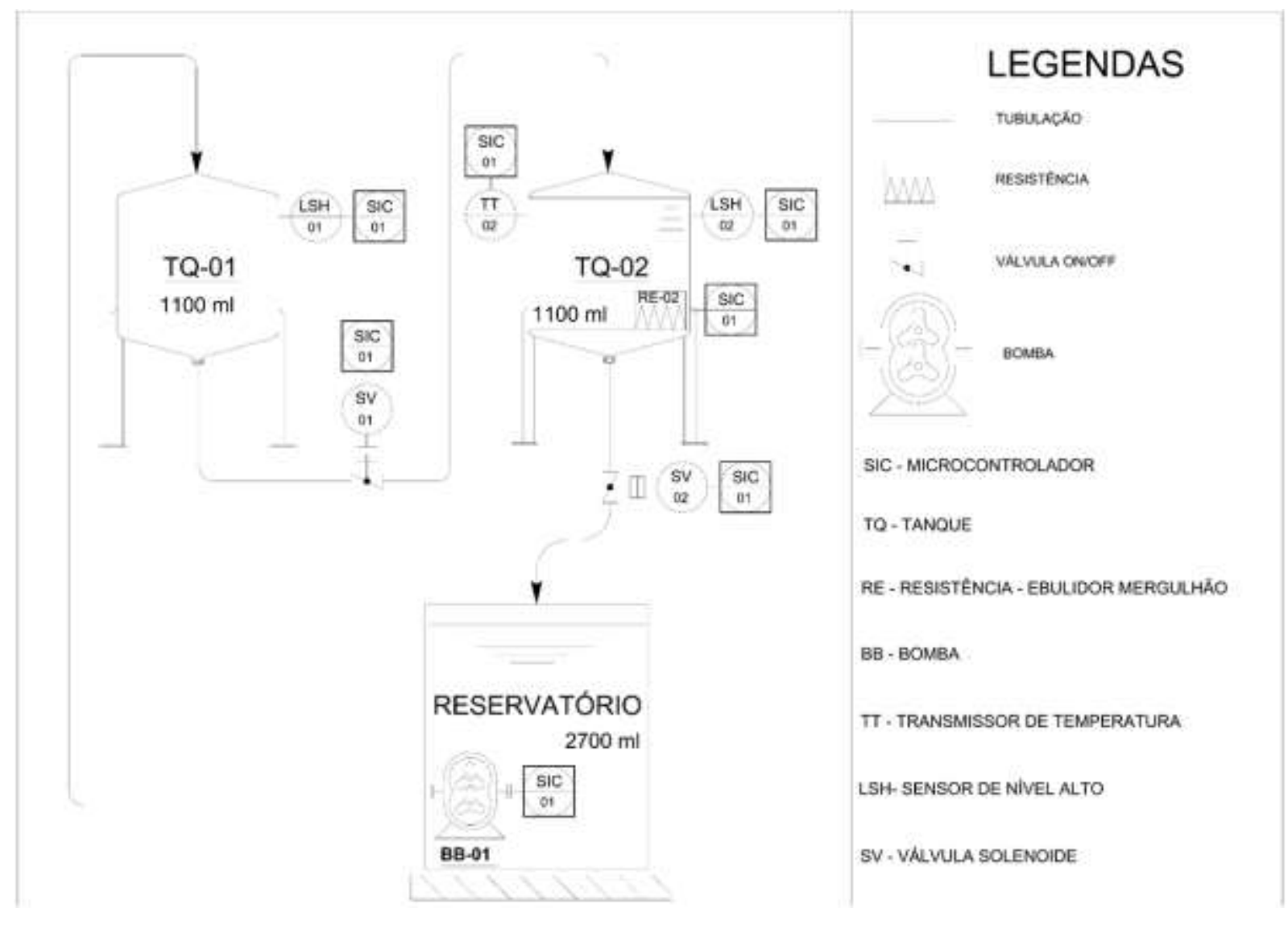

Fonte: Autores.

Figura 2. Vista Frontal da Bancada Didática.

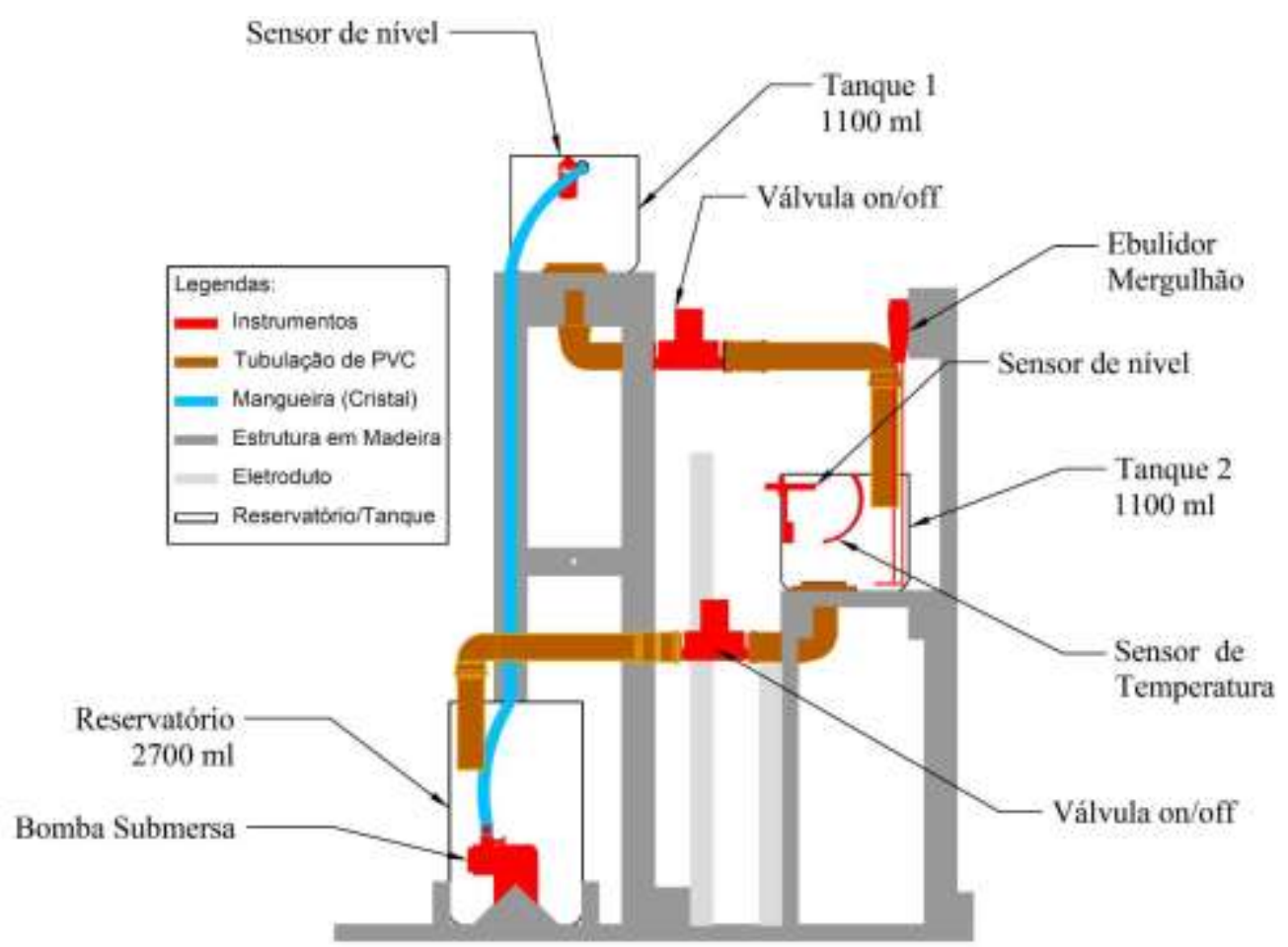

Fonte: Autores. 
Figura 3. Vista superior da Bancada Didática.

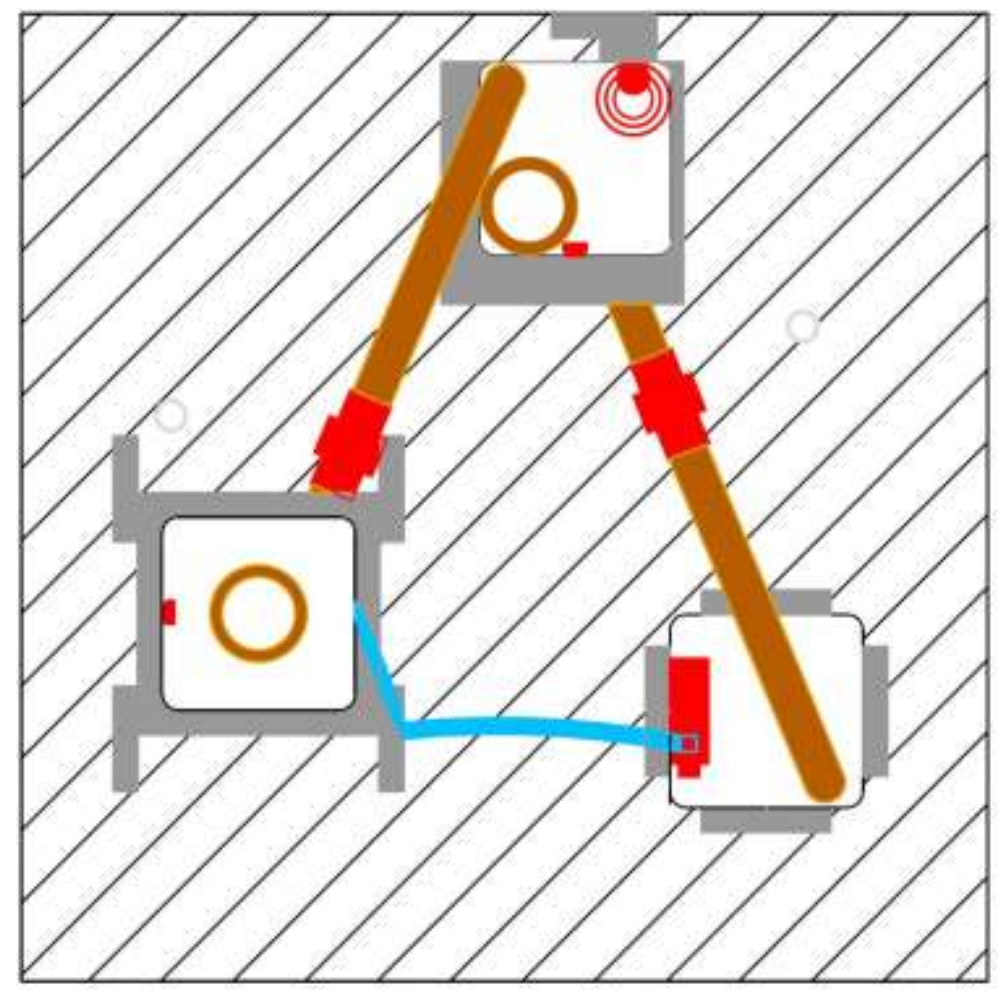

Fonte: Autores.

As ligações elétricas da bancada foram feitas com cabos de dimensão $0,75 \mathrm{~mm}^{2}$ para sensores e $2,5 \mathrm{~mm}^{2}$ para atuadores. Os circuitos passaram por eletrodutos de PVC rígido antichama de 1/2”.

Na bancada didática todo circuito de alimentação tem tensão de $220 \mathrm{~V}$ monofásico, usando um circuito por atuador. Os circuitos de comando são de 5,0 V, alimentados via portas do Arduino. O Arduino é uma plataforma de hardware open source, fácil de usar, ideal para a criação de dispositivos que permitam interação com o ambiente (Souza, 2011). Na Figura 4 pode-se verificar o esquemático com ligações elétricas da bancada didática.

Conforme o esquemático da Figura 4 o disjuntor de entrada Q1 distribui os cinco circuitos usados na bancada didática, o primeiro para o Arduino e os demais para os quatro relés que permitem alimentação da bomba, válvulas e resistência. O Arduino distribui os sete circuitos de comando, são eles: termopar, sensor de nível (Tanque 1), sensor de nível (Tanque 2) e os comandos dos quatro relés do projeto. 
Figura 4. Esquemático de ligações elétricas da bancada didática.

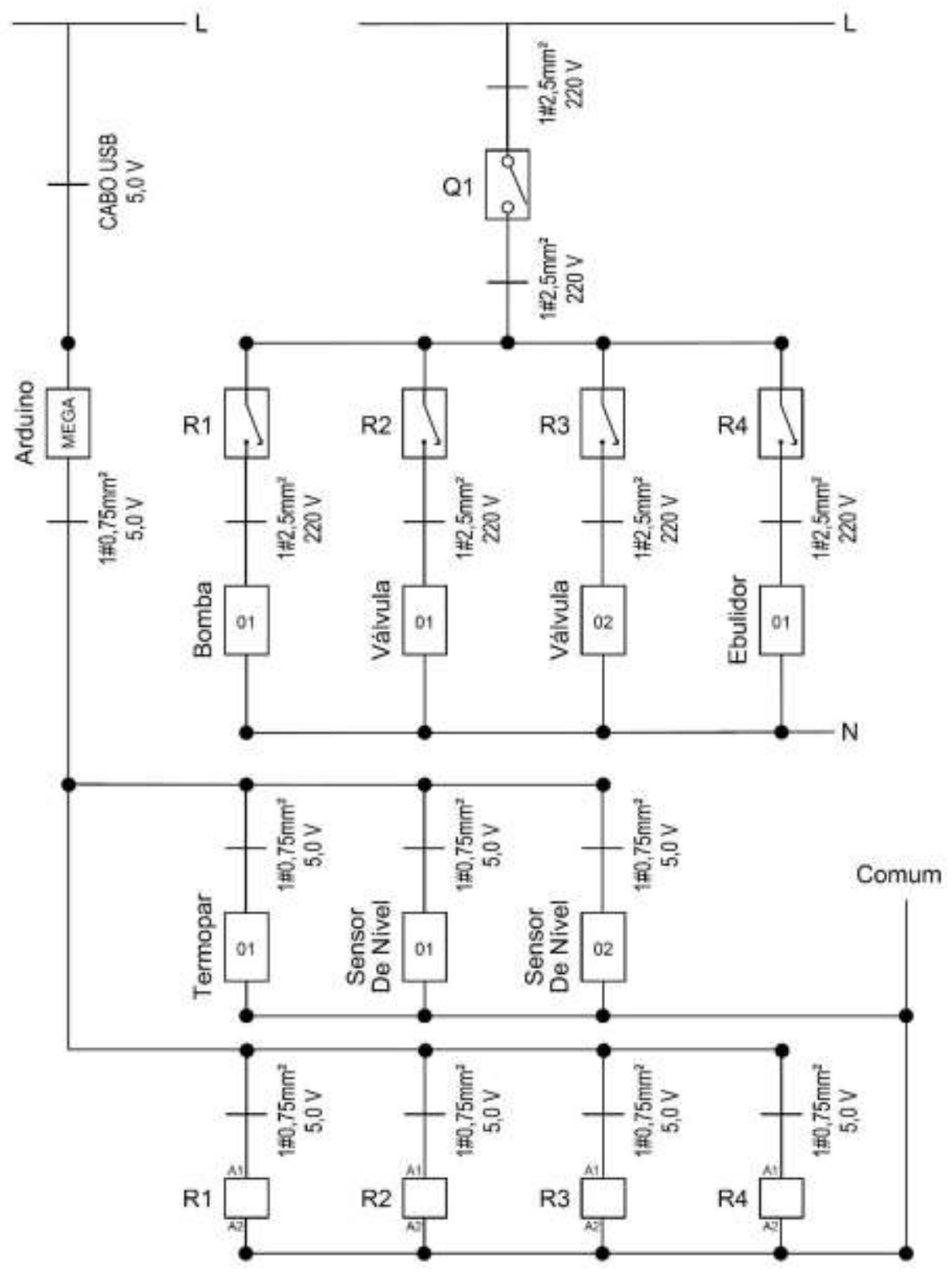

Fonte: Autores.

\subsection{Descrição dos ensaios na bancada didática}

Para que fosse possível verificar o funcionamento da bancada didática, foram projetados dois ensaios. O primeiro ensaio foi pensado para se trabalhar com a variável de processos de nível. No segundo ensaio, além da variável de nível, foi adicionado a variável temperatura.

Ao finalizar os experimentos será obtido um tempo para cada parte do processo, utilizando um cronômetro. Conhecendo o tempo, volume e temperatura dos processos, pode-se calcular a vazão da água no processo. As aplicações dos processos na bancada didática serão ideais para testar conhecimentos de física e instrumentação industrial.

\subsubsection{Ensaio 1}

O Ensaio 1 consiste em utilizar uma bomba submersa, válvulas solenoides e sensores de nível. O propósito dele é através dos sensores de nível enviar um sinal ao Arduino para acionar as válvulas solenoides. 
No início do processo o reservatório estará cheio de água. A água contida no reservatório irá para o Tanque 1, através de bombeamento. No Tanque 1 há na extremidade superior um sensor de nível para indicar quando o tanque estará cheio. Quando houver indicação que o tanque está cheio, haverá a abertura da válvula on/off entre o Tanque 1 e o Tanque 2.

No Tanque 2 também há um sensor de nível, quando o mesmo indica que o tanque está cheio será acionada uma válvula on/off que possibilita a passagem da água para o reservatório. A Figura 5 ilustra o fluxo lógico do Ensaio 1.

Figura 5. Fluxo lógico de ensaio 1 da bancada didática.

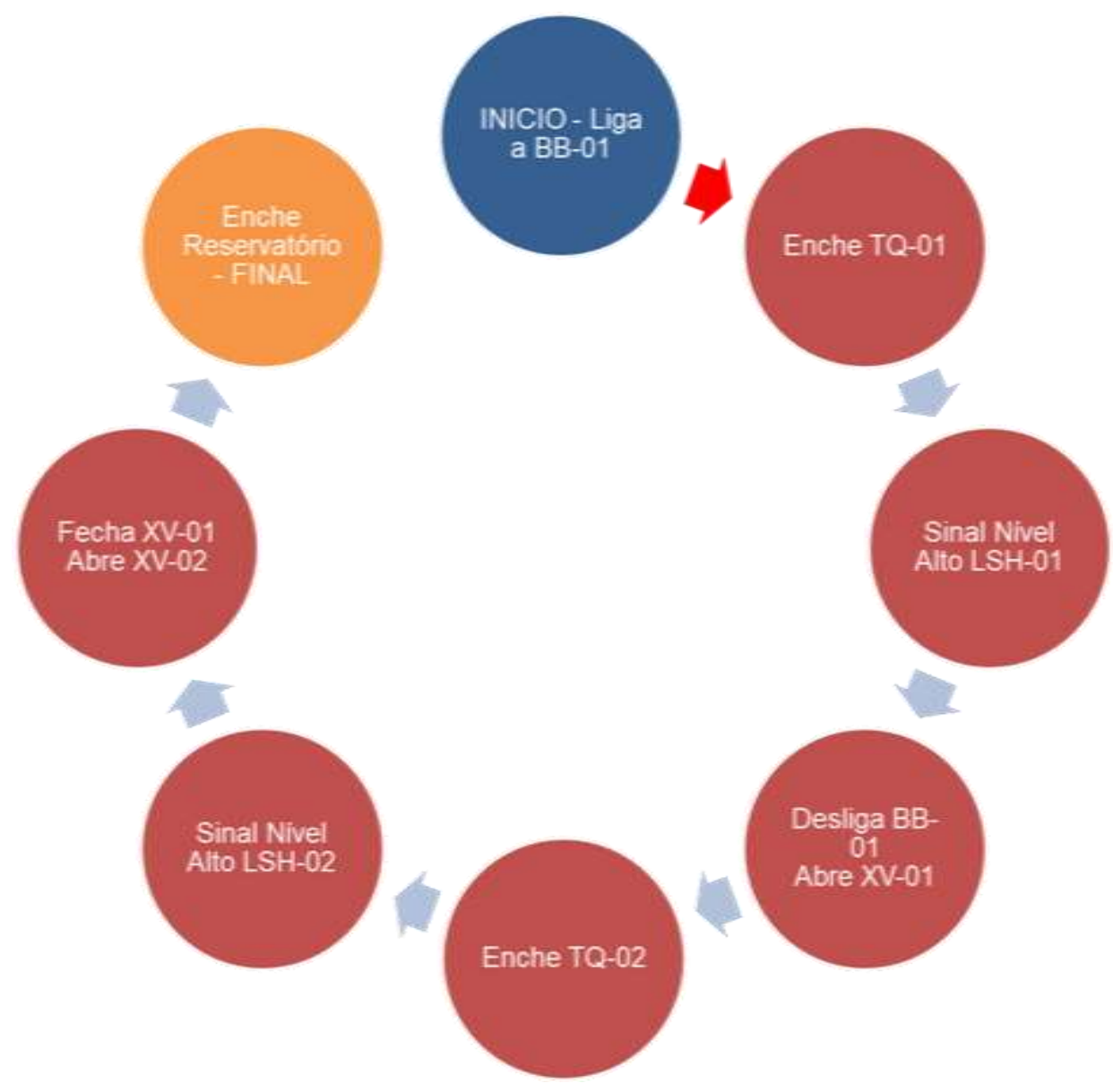

Fonte: Autores.

\subsubsection{Ensaio 2}

O Ensaio 2 consiste, assim como o Ensaio 1, em utilizar uma bomba submersa, válvulas solenoides e sensores de nível, mas também sensor de temperatura e ebulidor tipo mergulhão. O propósito dele é através do sensor de nível 1 enviar um sinal ao Arduino para acionar a válvula 1 e o sensor de nível 2 enviar o sinal para a ativação da resistência. Por sua vez, o sensor de temperatura enviará o sinal ao Arduino para acionar a válvula 2.

No início do processo o reservatório estará cheio de água. Então a bomba será acionada para bombear a água para o Tanque 1 e quando o sensor de nível indicar para o Arduino que está cheio a válvula entre os tanques irá abrir. Quando o sensor de nível no Tanque 2 indicar que o tanque está cheio, o microcontrolador irá fechar a válvula.

A ebulidor mergulhão só irá funcionar quando o sensor de nível do Tanque 2 indicar que está cheio e então será ligado aquecendo a água até a temperatura de $40{ }^{\circ} \mathrm{C}$ que será verificada pelo sensor de temperatura (Termopar Max 6675) e comunicará com o microcontrolador. Quando a temperatura prevista for atingida, a válvula on/off será aberta, assim a água irá para o reservatório. A Figura 6 ilustra o fluxo lógico do Ensaio 2. 
Figura 6. Fluxo lógico de ensaio 2 da bancada didática.

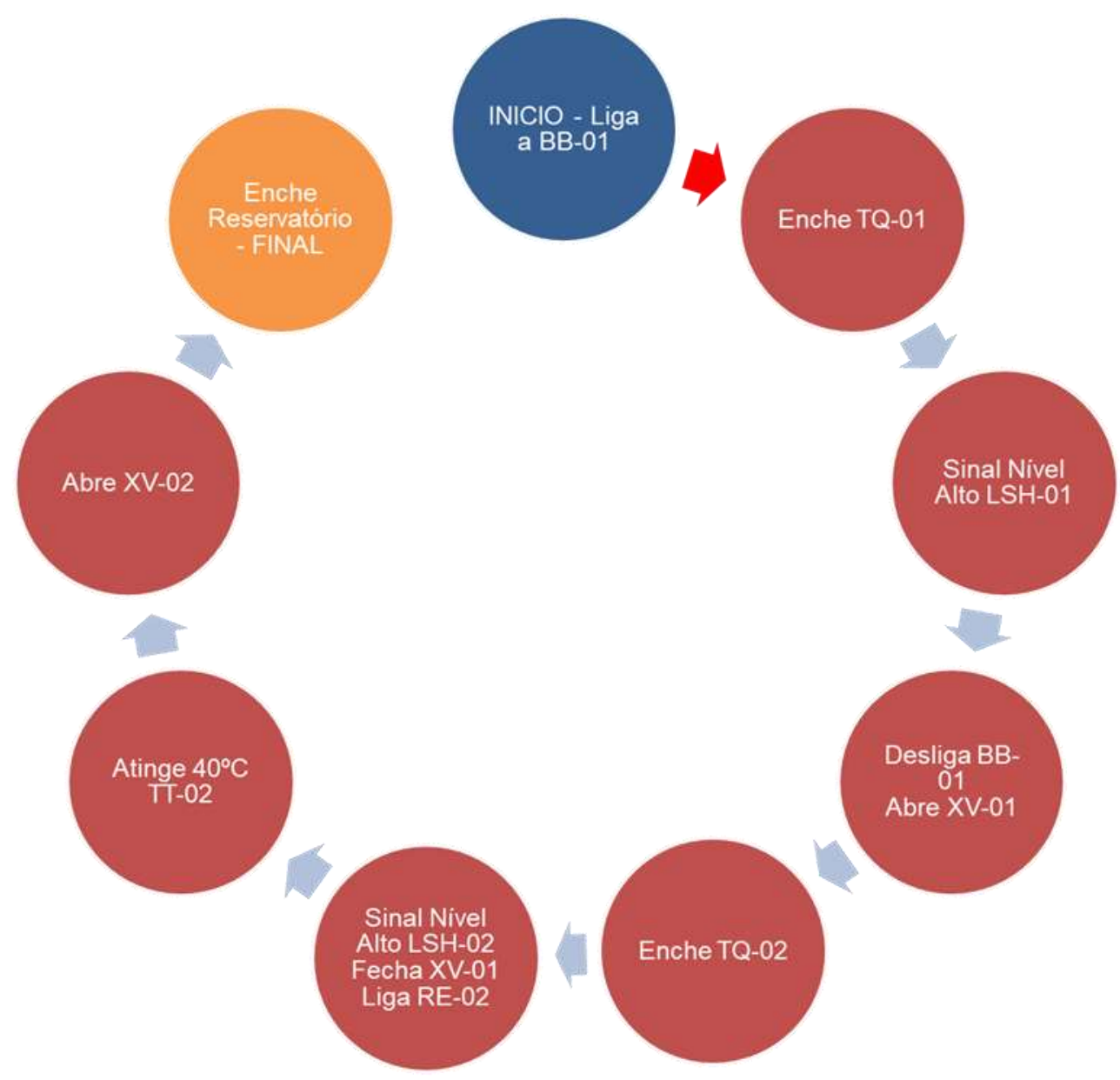

Fonte: Autores.

\section{Resultados}

Esse capítulo descreve os resultados da construção da bancada didática. Apresenta toda a parte estrutural e eletrônica. Bem como os resultados dos experimentos realizados na bancada didática.

\subsection{Montagem Da Bancada Didática}

Para a construção dos circuitos, dividimos em duas partes. Primeiro as ligações de força, para alimentação dos atuadores e do microcontrolador ilustrado na Figura 7. Em segundo, as ligações de comandos que são as ligações dos equipamentos eletrônicos no microcontrolador apresentado na Figura 8. 
Figura 7. Ligações para força.

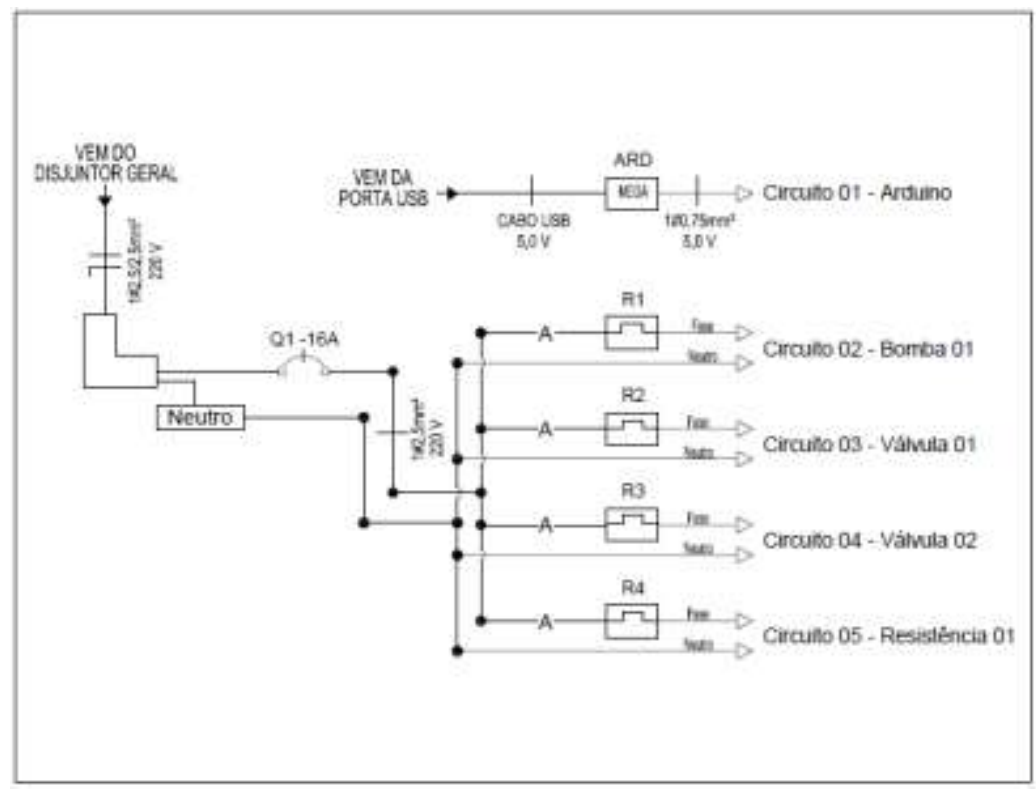

Fonte: Autores.

Figura 8. Ligações de comando.

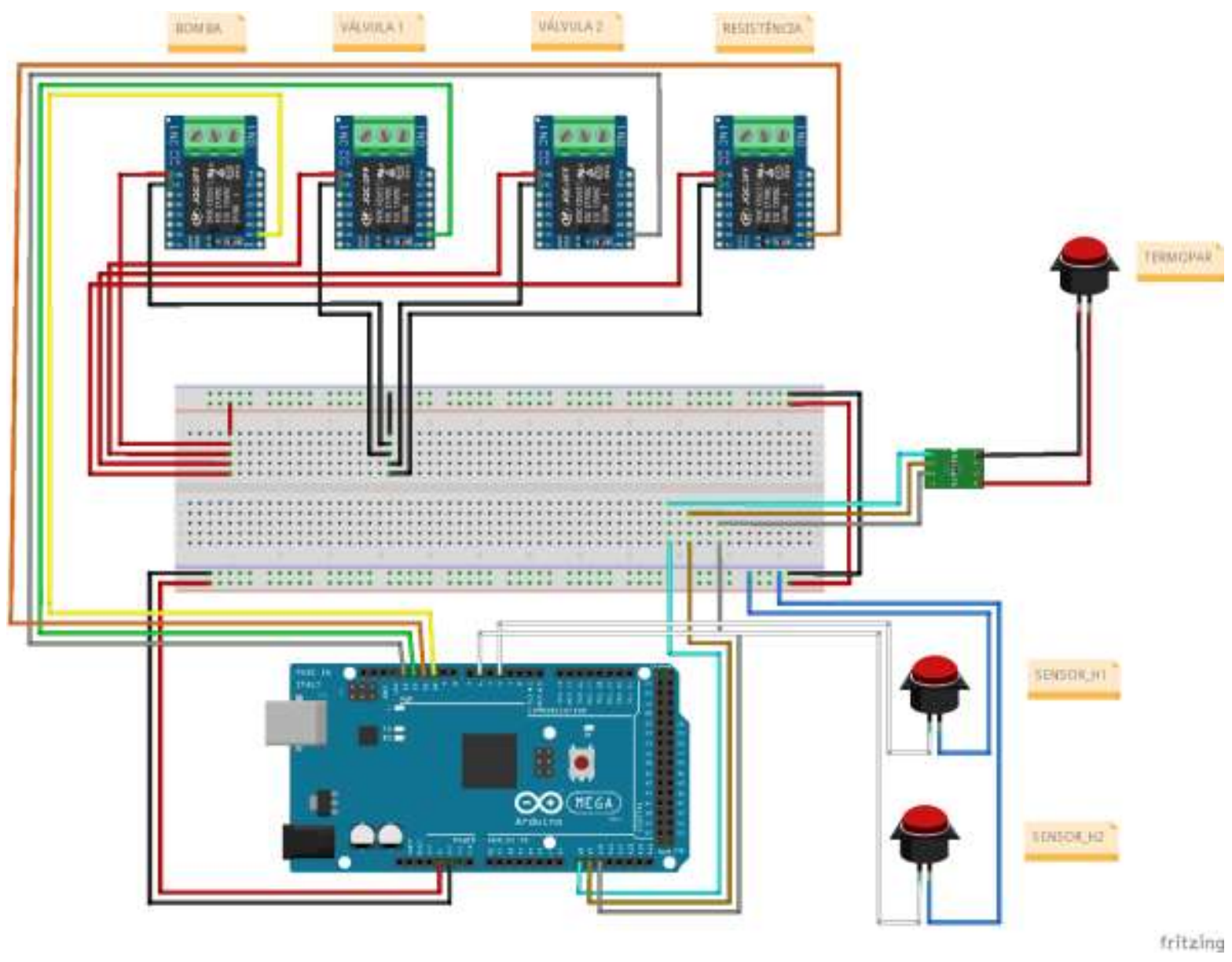

Fonte: Autores.

O microcontrolador utilizado na bancada foi o Arduino Mega 2560. O circuito conta com 5 relés com tensão máxima de saída de 250 Vca e corrente em 10 A, e bobina de acionamento de 5 Vcc como ilustrado na Figura 15. Também faz parte do 
circuito a ligação com um Termopar, com um conversor MAX6675 e dois sensores de nível tipo boia.

Para produção dos Tanques 1 e 2, foram usados recipientes em acrílico com capacidade para $1100 \mathrm{ml}$. Foi usado um flange no fundo do recipiente, o que ocasionou um volume morto de $200 \mathrm{ml}$. Com o sensor posicionado no topo do recipiente, nos sobrou um volume de $750 \mathrm{ml}$ para realização dos processos.

$\mathrm{O}$ circuito de força, contém um disjuntor de $16 \mathrm{~A}$, duas válvulas solenoide de $220 \mathrm{~V}$, uma resistência de aquecimento e uma bomba de água. A ligação é feita por meio de um cabo de cobre de $2,5 \mathrm{~mm}^{2}$.

Toda parte estrutural da bancada foi construída com madeira de MDF de 50mm de espessura, dispostos em uma base de $600 \mathrm{~mm}$ x 600mm. O Tanque 1 fica em uma plataforma a $620 \mathrm{~mm}$ de altura. Sua base é quadrada com $140 \mathrm{~mm}$ x $140 \mathrm{~mm}$. Da mesma forma, o Tanque 2 está em uma plataforma com $70 \mathrm{~mm}$ de altura, e apoiado em uma base quadrada de $180 \mathrm{~mm}$ x $180 \mathrm{~mm}$. A fixação de toda estrutura foi feita com parafusos de $6 \mathrm{~mm}$ e alguns apoios de $90^{\circ}$ também produzidos em madeira MDF de $5 \mathrm{~mm}$. A Figura 9 ilustra a bancada didática voltada para instrumentação industrial finalizada.

Figura 9. Bancada didática finalizada.

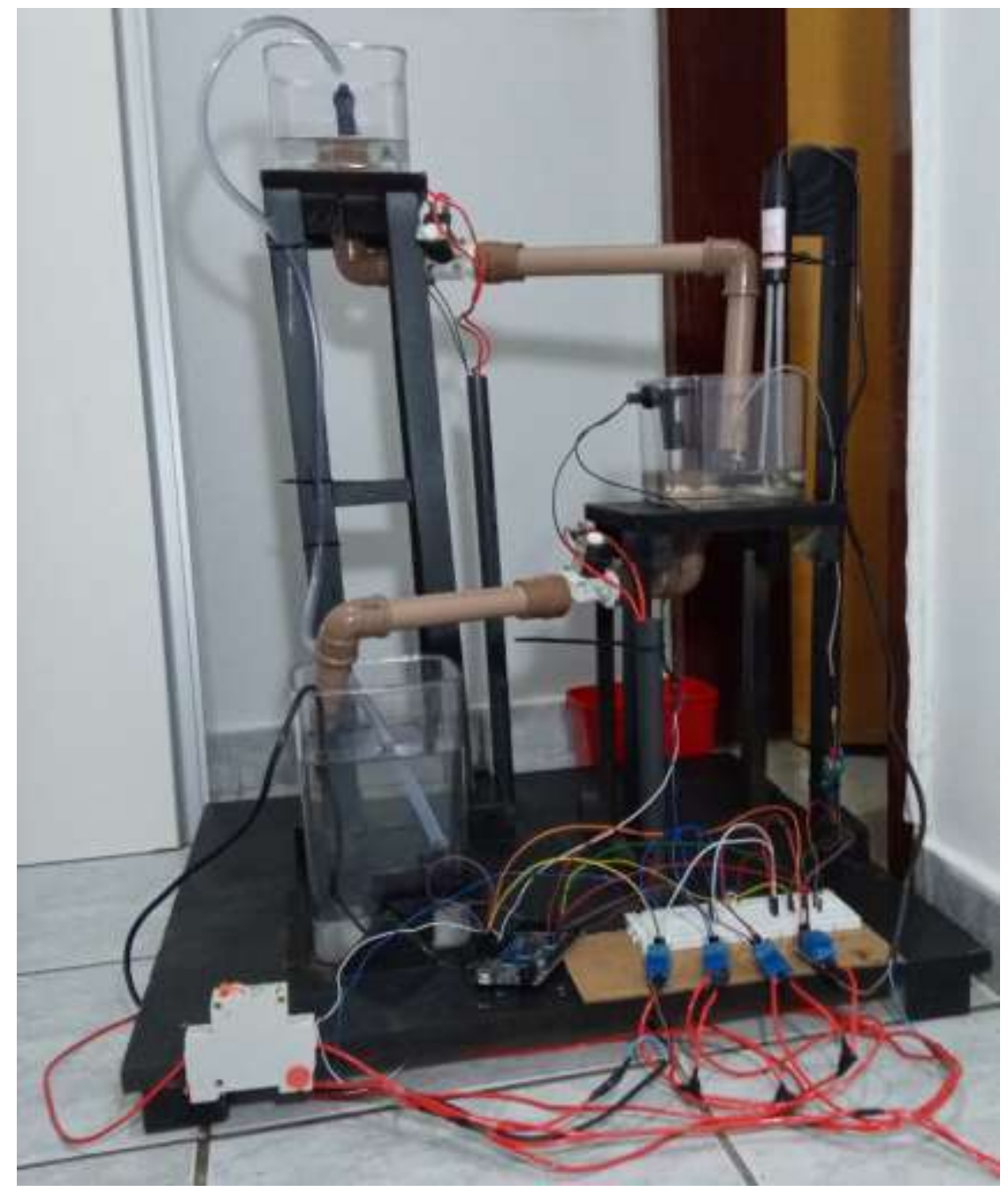

Fonte: Autores.

\subsection{Resultados dos Ensaios}

Com a bancada didática finalizada, iniciou-se os testes dos dois ensaios já pré-definidos na Seção 3.2. Testou-se inicialmente o Ensaio 1 que para facilitar a compreensão foi feito um Roteiro de experimento anexado no Apêndice C. O Ensaio 2 também foi roteirizado, sendo anexado no Apêndice D. A seguir, será mostrado os resultados obtidos por testes 
realizados pelos autores do presente trabalho.

\subsubsection{Resultado Ensaio 1}

Neste Ensaio a variável a ser controlada foi o nível. O reservatório foi enchido de água, e através do código implementado no microcontrolador Arduino, a bomba foi acionada e começou a esvaziar o reservatório e consequentemente encher o Tanque 1 até atingir o sensor de nível localizado na extremidade superior do mesmo. Esse processo durou cerca de $35,36 \mathrm{~s}$.

Ao atingir o sensor no Tanque 1, automaticamente desligou-se a bomba e foi aberta a válvula on/off localizada entre o Tanque 1 e o Tanque 2. Então, começou-se a esvaziar o Tanque 1 e encher o Tanque 2, levando um tempo de aproximadamente 7 min e 54 s para a água atingir o sensor de nível alto no Tanque 2.

Finalmente, atingindo o sensor de nível do Tanque 2, foi fechada a válvula entre o Tanque 1 e o Tanque 2, e em contrapartida aberta a válvula localizada entre o Tanque 2 e o Reservatório. Também foi acionada a bomba, que por sua vez, como no início do processo, enche o Tanque 1 até a água atingir o sensor de nível alto do Tanque 1, repetindo o ciclo do processo. Essa parte do processo levou cerca de 8 min e $13 \mathrm{~s}$.

Durante o teste foram obtidos resultados satisfatórios tendo em vista apenas o uso da força gravitacional para auxiliar na vazão entre os tanques. Com os valores de tempo obtidos e o volume conhecido dos tanques, foi calculado a vazão média neste Ensaio, considerando a Equação 1:

$$
\mathrm{Q}=\mathrm{V} / \mathrm{t}
$$

onde, Q é a vazão $\left(\mathrm{cm}^{3} / \mathrm{s}\right)$, V é o volume $\left(\mathrm{cm}^{3}\right)$ e t o tempo (s) (Delmée, 2003);(Walker, 2009).

Assim, aplicando os valores dos tempos obtidos e dos volumes conhecidos dos tanques, foi encontrada uma vazão de $1,47 \mathrm{~cm}^{3} / \mathrm{s}$.

\subsubsection{Resultado Ensaio 2}

No Ensaio 2, além de ser controlado o nível, foi adicionada outra variável, que foi a temperatura. O código anexado ao Apêndice B, foi configurado para abranger o controle da temperatura, e colocado para rodar iniciando o Ensaio 2.

O começo desse processo, é exatamente igual ao Ensaio 1, bomba é acionada, enche o Taque 1 e quando atingir o sensor de nível alto, abre a primeira válvula e enche o Tanque 2. Os tempos para encher o Tanque 1 e posteriormente encher o Tanque 2, foram 33,83 s e 6 min e 47 s, respectivamente.

No Tanque 2 apresentou-se uma diferença em relação ao Ensaio 1, quando encheu-se e atingir o sensor de nível alto, não foi acionado a válvula, no lugar foi acionado uma resistência localizada dentro do tanque, para aquecer a água. Quando a temperatura da água atingiu $40^{\circ} \mathrm{C}$, registado pelo sensor de temperatura que está localizado no Tanque 2, a válvula entre o Tanque 2 e o Reservatório foi aberta. Os tempos que duraram o processo de aquecimento da água e esvaziar o Tanque 2 foram respectivamente, 8 min e $14 \mathrm{~s}$, e 8 min e $46 \mathrm{~s}$.

Como no Ensaio 1, o Ensaio 2 também foi aplicado a Equação 1 e encontrado a vazão média de 1,02 cm³/s.

\section{Conclusão}

O presente trabalho cumpriu com o que foi proposto, de utilizar conhecimentos de instrumentação industrial adquiridos nos cursos de engenharia para desenvolver uma bancada didática.

Com os resultados obtidos, pode-se calcular a vazão e deixar em aberto para cálculos de pressão e aplicações de 
exercícios de física e instrumentação na bancada didática. A aplicação ficará a critério do docente responsável da aula, sendo assim a bancada satisfaz o proposto, que é auxiliar os discentes a executar a teoria na prática.

Como trabalhos futuros é proposto a implementação de um sistema supervisório onde ele será capaz de fazer a aquisição de dados e monitoramento e controle de todas as variáveis da planta. Novos sensores e atuadores, assim, podemos trabalhar nossos processos e incluir novas etapas nos processos já propostos, podendo assim, apresentar aplicações de conhecimentos de manufatura e de usinagem na melhoria da estrutura da bancada didática.

\section{Referências}

Alpi, L. B. (2016). Desenvolvimento de uma planta didática para o controle de nível de tanques acoplados. Monografia apresentada como requisito parcial para a obtenção do grau de Bacharel em Engenharia de Computação.

Anabuki, E. T. (2019). Aprendizagem baseada em problemas e aprendizagem colaborativa no ensino de engenharia de controle e automação. Revista de Estudos e Pesquisas sobre Ensino Tecnológico (EDUCITEC), 5(10).

Anderle, B. P. (2017). Dimensionamento de uma Bancada Didática de Hidráulica.

Delmée, G. J. (2003). Manual de medição de vazão. Editora Blucher.

Dunn, W. C. (2013). Fundamentos de instrumentação industrial e controle de processos. Bookman Editora.

Educação, D. Lei n 9.394, de 20 de dezembro de 1996. Estabelece as diretrizes e bases da.

Estrela, C. (2018). Metodologia científica: ciência, ensino, pesquisa. Artes Médicas.

Fabián, G. G. (2017). Desenvolvimento de bancada didática voltada ao estudo de Sistemas pneumáticos.

Feisel, L. D., \& Rosa, A. J. (2005). The role of the laboratory in undergraduate engineering education. Journal of engineering Education, 94(1), 121-130.

Goulart, H. S. (2008). Desenvolvimento de Bancada Didática para Estudos de Desempenho Térmico de um Trocador de Calor Compacto Aletado.

ISA (International Society of Automation). (2002). Safety Instrumented Functions (SIF)-Safety Integrity Level (SIL) Evaluation Techniques.

Lima, I. A. M. (2014) Proposição de uma bancada didática para análise de vibração em manutenção preditiva. 2014.83 f., il. Trabalho de conclusão de curso (Bacharelado em Engenharia Automotiva). Universidade de Brasília, Brasília.

Marques, J. L., Spacek, A. D., Neto, J. M., \& Junior, O. H. A. (2018). Proposta de uma bancada de baixo custo para o ensino de automação industrial de acordo com as normas de segurança. Revista de Ensino de Engenharia, 36(2).

Pereira, A. S., Shitsuka, D. M., Parreira, F. J., \& Shitsuka, R. (2018). Metodologia da pesquisa científica. UFSM. https://repositorio. ufsm. br/bitstream/handle/1/15824/Lic_Computacao_Metodologia-Pesquisa-Cientifica. pdf.

Souza, A. R. D., Paixão, A. C., Uzêda, D. D., Dias, M. A., Duarte, S., \& Amorim, H. S. D. (2011). A placa Arduino: uma opção de baixo custo para experiências de física assistidas pelo PC. Revista Brasileira de Ensino de Física, 33(1), 01-05.

Teixeira, A. L., Scherer, L. G., \& Gorretti, A. A. T. (2018). Projeto de bancadas didáticas para laboratório de instalações elétricas.

Toigo, É. (2017). Desenvolvimento do projeto de uma bancada didática de refrigeração por compressão de vapor.

Walker, J., Halliday, D., \& Resnick, R. (2009). Fundamentos de física: volume 2: gravitação, ondas e termodinâmica. LTC.

Yin, R. K. (2015). Estudo de Caso-: Planejamento e métodos. Bookman editora.

Zorzan, F. B., Daronch, J., \& Molin, A. (2013). Desenvolvimento de uma Bancada Didática de Hidráulica. Fórum Latino Americano De Engenharia. UNILA. 